\title{
Polyquinolines Containing Both Spirobifluorene and Cardofluorene Units: Synthesis and Characterization
}

\author{
CHING-HSIN CHEN, CHING-FONG SHU \\ Department of Applied Chemistry, National Chiao Tung University, Hsin-Chu, Taiwan, 30035
}

Received 8 March 2004; accepted 8 March 2004

DOI: 10.1002/pola.20179

Published online in Wiley InterScience (www.interscience.wiley.com).

\begin{abstract}
We have synthesized aromatic polyquinolines containing both spirobifluorene and cardofluorene moieties in the main chain by applying acid-catalyzed Friedländer quinoline synthesis. The incorporation of these rigid nonplanar structures into the polymer backbone, which restricts segmental mobility, significantly increases both the glass-transition temperature and thermal stability, while providing enhanced solubility as a result of a decrease in the degree of molecular packing and crystallinity. We have also examined the optical and electrochemical properties of these polyquinolines. The low-lying lowest unoccupied molecular orbital energy level and quasireversible electrochemical reduction of these polyquinolines suggest their potential for use as electron-injecting/transporting materials in polymer light-emitting diodes. ( 2004 Wiley Periodicals, Inc. J Polym Sci Part A: Polym Chem 42: 3314-3322, 2004
\end{abstract}

Keywords: electrochemistry; fluorescence; light-emitting diodes (LED); polyquinolines; solution properties; thermal properties

\section{INTRODUCTION}

Polyquinolines, a class of high-performance polymer materials developed by Stille ${ }^{1}$ in the 1970 s, are thermally stable and mechanically strong. Because of their excellent optical and electronic properties, ${ }^{2,3}$ these polymers have recently been explored extensively as potentially useful materials in electronic and photonic applications, such as organic light-emitting diodes, ${ }^{4-12}$ thin-film transistors, ${ }^{13}$ photovoltaic cells, ${ }^{14}$ nonlinear optical devices, ${ }^{15-21}$ and optical sensors. ${ }^{22-24}$

Although rigid-rod polyquinolines exhibit high strength and possess excellent thermal properties, they have limited solubility in organic solvents, and this makes fabrication difficult. ${ }^{25,26} \mathrm{In}$ attempts to enhance the solubility of polyquino-

Correspondence to: C.-F. Shu (E-mail: shu@cc.nctu.edu.tw) Journal of Polymer Science: Part A: Polymer Chemistry, Vol. 42, 3314-3322 (2004) () 2004 Wiley Periodicals, Inc. lines, long alkyl side chains, ${ }^{27,28}$ flexible ether linkages, ${ }^{29}$ cardo units, ${ }^{30,31}$ and spiro moieties ${ }^{32}$ have all been incorporated into the polymer backbone. Generally, phenylated polyquinolines are synthesized by acid-catalyzed Friedländer condensation reactions of bis(o-aminoketone)s with bisacetyl monomers. ${ }^{33-35}$ This synthetic route provides a great degree of flexibility for introducing various structural features into the backbone of the polymers. In this article, we report the synthesis of polyquinolines that contain both spirobifluorene and cardofluorene moieties in the polymer main chain, which we have prepared with acid-catalyzed Friedländer quinoline synthesis. The bifluorene rings in the spiro segment are orthogonally arranged and connected via a common tetracoordinated carbon atom. ${ }^{36-39}$ The pendent fluorenyl loop in the cardo segment lies perpendicular to the planar aromatic backbone..$^{30,40,41}$ We expected that these structural features would reduce the probability of inter- 
chain interactions and prevent the close packing of polymer chains, and this would impart good solubility to the polymers. Additionally, we expected the incorporation of these rigid nonplanar structures into the polymer backbone to restrict segmental mobility and result in a significant improvement in both the glass-transition temperature $\left(T_{\mathrm{g}}\right)$ and thermal stability. Furthermore, the $\mathrm{sp}^{3}$-hybridized carbon atoms that are present at the spiro and cardo centers connect the conjugated moieties via a $\sigma$-bonded network and serve as spacers and conjugation interrupts and thus effectively control the conjugation length of the polymers. ${ }^{32,42}$ We have studied the basic properties of these new polyquinolines, such as their thermal properties and solubility. Because of the electron-deficient nature of the quinoline ring, ${ }^{43}$ polyquinolines and their copolymers have been demonstrated to be electron-injecting/transporting materials in organic light-emitting diode devices. ${ }^{4-8}$ In light of these observations, we have also explored the optical and electrochemical properties of these new polyquinolines.

\section{EXPERIMENTAL}

\section{Materials}

Monomers $5^{32}$ and $\mathbf{6}^{44}$ and compound $7^{32}$ were prepared as described in the literature. $m$-Cresol was purified by distillation under reduced pressure. Tetrabutylammonium hexafluorophosphate was purified by recrystallization from ethyl acetate and dried in vacuo at $60{ }^{\circ} \mathrm{C}$. All other chemicals were used as received unless otherwise stated.

\section{Characterization}

${ }^{1} \mathrm{H}$ and ${ }^{13} \mathrm{C}$ NMR spectra were recorded on a Varian Unity $300-\mathrm{MHz}$ spectrometer or a BrukerDRX $300-\mathrm{MHz}$ spectrometer with $\mathrm{CDCl}_{3}$ as the solvent. Mass spectra were obtained on a JEOL JMS-SX/SX 102A mass spectrometer. Size exclusion chromatography was performed on a Waters chromatography unit interfaced with a Waters 410 differential refractometer, with three $5-\mu \mathrm{m}$ Waters Styragel columns $(300 \times 7.8 \mathrm{~mm})$ connected in series in order of decreasing pore size $\left(10^{4}, 10^{3}\right.$, and $10^{2} \AA$ ); tetrahydrofuran (THF) was the eluent, and standard polystyrene samples were used for calibration. Differential scanning calorimetry (DSC) was performed on a Seiko SSC $5200 \mathrm{DSC}$ unit at heating and cooling rates of 20 and $40{ }^{\circ} \mathrm{C} \mathrm{min}{ }^{-1}$, respectively. The samples were scanned from 30 to $500{ }^{\circ} \mathrm{C}$, cooled to $30{ }^{\circ} \mathrm{C}$, and scanned for a second time from 30 to $500{ }^{\circ} \mathrm{C}$. $T_{\mathrm{g}}$ 's were determined from the second heating scan. Thermogravimetric analysis (TGA) was carried out on a Dupont TGA 2950 instrument. The thermal stability of the samples was determined in nitrogen through the measurement of the weight loss at a heating rate of $10{ }^{\circ} \mathrm{C} \mathrm{min}{ }^{-1}$. The ultraviolet-visible (UV-vis) spectra were measured with an HP 8453 diode-array spectrophotometer. The photoluminescence (PL) spectra were obtained on a Hitachi F-4500 luminescence spectrometer. Cyclic voltammetry measurements of the polymer films were performed on a BAS 100 $\mathrm{B} / \mathrm{W}$ electrochemical analyzer in acetonitrile, with $0.1 \mathrm{M}$ tetrabutylammonium hexafluorophosphate as the supporting electrolyte, at a scanning rate of $100 \mathrm{mV} \mathrm{s}^{-1}$. The potentials were measured against an $\mathrm{Ag} / \mathrm{Ag}^{+}$( $0.01 \mathrm{M} \mathrm{AgNO}_{3}$ ) reference electrode with ferrocene as the internal standard. The onset potentials were determined from the intersection of two tangents drawn at the rising current and background current of the cyclic voltammogram.

\section{9,9-Bis(4-acetylphenyl)fluorene (1)}

A mixture of fluorene $(2.00 \mathrm{~g}, 12.0 \mathrm{mmol}), 4$-fluoroacetophenone $(4.15 \mathrm{~g}, 30.1 \mathrm{mmol}), \mathrm{K}_{2} \mathrm{CO}_{3}(6.64$ g, $48.1 \mathrm{mmol})$, [18]crown-6 (1.59 g, $6.02 \mathrm{mmol})$, benzene $(5.0 \mathrm{~mL})$, and $N, N$-dimethylformamide (DMF; $10 \mathrm{~mL}$ ) was heated at $150{ }^{\circ} \mathrm{C}$. The water that formed during the reaction was removed by azeotropic distillation and collected in a DeanStark trap. After $3 \mathrm{~h}$, the remaining benzene in the reaction mixture was removed by distillation. The mixture was then heated under reflux for $20 \mathrm{~h}$, cooled, and poured into water $(300 \mathrm{~mL})$. The precipitated product was purified by column chromatography, eluting with hexane/ethyl acetate (3: 1 ); this was followed by recrystallization from ethyl acetate to yield $\mathbf{1}$ (3.05 g, 63.0\%).

${ }^{1} \mathrm{H} \mathrm{NMR}\left(\mathrm{CDCl}_{3}, \delta\right): 7.79(\mathrm{~d}, J=10.5 \mathrm{~Hz}, 4 \mathrm{H})$, $7.76(\mathrm{~d}, J=7.2 \mathrm{~Hz}, 2 \mathrm{H}), 7.36$ (ddd, $J=7.2,7.2$, and $1.2 \mathrm{~Hz}, 2 \mathrm{H}), 7.33-7.27(\mathrm{~m}, 4 \mathrm{H}), 7.23(\mathrm{~d}, J$ $=9.3 \mathrm{~Hz}, 4 \mathrm{H}), 2.51(\mathrm{~s}, 6 \mathrm{H}) .{ }^{13} \mathrm{C} \mathrm{NMR}\left(\mathrm{CDCl}_{3}, \delta\right)$ : $197.5,150.7,149.6,140.2,135.8,128.5,128.2$, 128.1, 125.9, 120.5, 65.5, 26.5. High-resolution mass spectrometry (HRMS): $\left[\mathrm{M}^{+}\right]$calcd. for $\mathrm{C}_{29} \mathrm{H}_{22} \mathrm{O}_{2}$, 402.1620; found, 402.1624. Elem. AnAL. 
Calcd. for $\mathrm{C}_{29} \mathrm{H}_{22} \mathrm{O}_{2}$ : C, 86.54\%; H, 5.51\%. Found: C, $86.42 \%$; H, $5.71 \%$.

\section{9,9-Bis(4-nitrophenyl)fluorene (2)}

A mixture of fluorene $(3.00 \mathrm{~g}, 18.0 \mathrm{mmol})$, 4-fluoronitrobenzene (5.68 g, $41.1 \mathrm{mmol}), \mathrm{K}_{2} \mathrm{CO}_{3}(5.98$ g, $43.4 \mathrm{mmol})$, [18]crown-6 (2.39 g, $9.09 \mathrm{mmol})$, benzene $(5.0 \mathrm{~mL})$, and DMF $(15 \mathrm{~mL})$ was heated at $150{ }^{\circ} \mathrm{C}$. The water that formed during the reaction was removed by azeotropic distillation and collected in a Dean-Stark trap. After $3 \mathrm{~h}$, the remaining benzene in the reaction mixture was removed by distillation. The mixture was then heated under reflux for $3 \mathrm{~h}$, cooled, and poured into water $(300 \mathrm{~mL})$. The precipitate was washed with water and recrystallized from ethyl acetate to give $2(6.65 \mathrm{~g}, 90.3 \%)$.

${ }^{1} \mathrm{H} \mathrm{NMR}\left(\mathrm{CDCl}_{3}, \delta\right): 8.09(\mathrm{~d}, J=9.0 \mathrm{~Hz}, 4 \mathrm{H})$, $7.81(\mathrm{~d}, J=7.5 \mathrm{~Hz}, 2 \mathrm{H}), 7.46-7.40(\mathrm{~m}, 2 \mathrm{H})$, 7.34-7.29 (m, 8 H). ${ }^{13} \mathrm{C} \mathrm{NMR}\left(\mathrm{CDCl}_{3}, \delta\right): 152.3$, $148.6,147.1,140.3,128.9,128.8,128.6,125.9$, 123.9, 121.0, 65.4. HRMS: $\left[\mathrm{M}^{+}\right]$calcd. for $\mathrm{C}_{25} \mathrm{H}_{16} \mathrm{~N}_{2} \mathrm{O}_{4}$, 408.1110; found, 408.1113. ELEM. ANAL. Calcd. for $\mathrm{C}_{25} \mathrm{H}_{16} \mathrm{~N}_{2} \mathrm{O}_{4}: \mathrm{C}, 73.52 \% ; \mathrm{H}$, $3.95 \%$; N, 6.86\%. Found: C, 73.46\%; H, 4.32\%; N, $6.80 \%$.

\section{9,9-Bis[5-(3-phenyl-2,1-benzisoxazolyl)] fluorene (3)}

Benzyl cyanide $(1.63 \mathrm{~mL}, 14.7 \mathrm{mmol}$ ) was added dropwise to an ice-cooled mixture of sodium hydroxide $(2.83 \mathrm{~g}, 70.8 \mathrm{mmol})$, methanol $(12 \mathrm{~mL})$, and THF (18 mL). After 5 min of stirring, compound $2(3.00 \mathrm{~g}, 7.35 \mathrm{mmol})$ was added slowly, and then the mixture was heated at $80{ }^{\circ} \mathrm{C}$ for $10 \mathrm{~h}$. Methanol $(20 \mathrm{~mL})$ was added to the reaction mixture, which was then cooled in an ice bath. The resulting precipitate was isolated by filtration and washed with a cold mixture of methanol $(10 \mathrm{~mL})$ and $\mathrm{H}_{2} \mathrm{O}(40 \mathrm{~mL})$. The crude product was recrystallized from ethyl acetate to afford compound $3(2.88 \mathrm{~g}, 71.0 \%)$.

${ }^{1} \mathrm{H}$ NMR $\left(\mathrm{CDCl}_{3}, \delta\right): 7.85(\mathrm{~d}, J=7.2 \mathrm{~Hz}, 2 \mathrm{H})$, 7.78-7.75 (m, $4 \mathrm{H}), 7.57-7.54(\mathrm{~m}, 4 \mathrm{H}), 7.51(\mathrm{dd}, J$ $=6.8,0.9 \mathrm{~Hz}, 2 \mathrm{H}), 7.47-7.41(\mathrm{~m}, 8 \mathrm{H}), 7.37-7.30$ $(\mathrm{m}, 4 \mathrm{H}) .{ }^{13} \mathrm{C} \mathrm{NMR}\left(\mathrm{CDCl}_{3}, \delta\right): 164.4,157.1,149.1$, $140.6,140.3,132.5,130.2,129.2,128.4,128.2$, $128.0,126.4,125.7,120.8,117.9,116.0,114.2$, 65.0. HRMS: $\left[\mathrm{M}^{+}\right]$calcd. for $\mathrm{C}_{39} \mathrm{H}_{24} \mathrm{~N}_{2} \mathrm{O}_{2}$, 552.1838; found, 552.1842. Elem. ANAL. Calcd. for $\mathrm{C}_{39} \mathrm{H}_{24} \mathrm{~N}_{2} \mathrm{O}_{2}$ : C, 84.76\%; H, 4.38\%; N, 5.07\%. Found: C, $84.62 \%$; H, $4.60 \%$; N, $5.01 \%$.

\section{9,9-Bis(4-amino-3-benzoylphenyl)fluorene (4)}

Iron powder $(0.75 \mathrm{~g}, 13.4 \mathrm{mmol})$ and water $(0.5$ $\mathrm{mL}$ ) were added to a stirred suspension of compound $3(1.00 \mathrm{~g}, 1.81 \mathrm{mmol})$ in acetic acid $(\mathrm{AcOH}$; $20 \mathrm{~mL}$ ) at $95^{\circ} \mathrm{C}$. The reaction mixture was heated at $95{ }^{\circ} \mathrm{C}$ for $1 \mathrm{~h}$, cooled, and filtered to remove the iron powder. The filtrate was poured into water $(100 \mathrm{~mL})$. The resulting precipitate was collected by filtration and recrystallized from methylene chloride $\left(\mathrm{CH}_{2} \mathrm{Cl}_{2}\right)$ to give $4(910 \mathrm{mg}, 90.4 \%)$.

${ }^{1} \mathrm{H} \mathrm{NMR}\left(\mathrm{CDCl}_{3}, \delta\right): 7.61(\mathrm{~d}, J=7.3 \mathrm{~Hz}, 2 \mathrm{H})$, $7.43-7.39(\mathrm{~m}, 6 \mathrm{H}), 7.30(\mathrm{~d}, J=7.3 \mathrm{~Hz}, 4 \mathrm{H})$, $7.26-7.20(\mathrm{~m}, 6 \mathrm{H}), 7.17(\mathrm{~m}, 2 \mathrm{H}), 7.10(\mathrm{dd}, J$ $=8.6,2.3 \mathrm{~Hz}, 2 \mathrm{H}), 6.56(\mathrm{~d}, J=8.6 \mathrm{~Hz}, 2 \mathrm{H}) .{ }^{13} \mathrm{C}$ $\mathrm{NMR}\left(\mathrm{CDCl}_{3}, \delta\right): 198.6,151.1,149.5,139.9,139.5$, $134.1,133.9,132.4,131.2,129.3,127.9,127.6$, 127.5, 125.6, 120.2, 117.7, 117.1, 63.3. HRMS: $\left[\mathrm{M}^{+}\right]$calcd. for $\mathrm{C}_{39} \mathrm{H}_{28} \mathrm{~N}_{2} \mathrm{O}_{2}, 556.2151$; found, 556.2146. Elem. Anal. Calcd. for $\mathrm{C}_{39} \mathrm{H}_{28} \mathrm{~N}_{2} \mathrm{O}_{2}$ : C, $84.15 \%$; H, $5.07 \%$; N, $5.03 \%$. Found: C, $84.14 \%$; H, $5.36 \% ; \mathrm{N}, 5.01 \%$.

\section{Polyquinoline PQ1}

A mixture of bisacetyl monomer 1 (200 mg, 497 $\mu \mathrm{mol})$, bis(o-aminoketone) monomer 5 (275 $\mathrm{mg}$, $497 \mu \mathrm{mol}$ ), diphenyl phosphate (DPP; $3.00 \mathrm{~g}, 12.0$ $\mathrm{mmol})$, and freshly distilled $m$-cresol $(0.6 \mathrm{~mL})$ was flushed with nitrogen while stirring for about 20 min and then was heated at $140{ }^{\circ} \mathrm{C}$ for $72 \mathrm{~h}$ under a nitrogen atmosphere. After cooling, the resulting viscous solution was diluted with chloroform $\left(\mathrm{CHCl}_{3} ; 2.0 \mathrm{~mL}\right)$ and added dropwise to an agitated solution of $10 \%(\mathrm{v} / \mathrm{v})$ triethylamine in methanol $(110 \mathrm{~mL})$. The collected polymer was purified by being precipitated three times from $\mathrm{CHCl}_{3}(2.0$ $\mathrm{mL})$ into a $10 \%(\mathrm{v} / \mathrm{v})$ triethylamine solution in methanol $(150 \mathrm{~mL})$. With a Soxhlet extractor, the polymer was then extracted continuously with a $10 \%(\mathrm{v} / \mathrm{v})$ triethylamine solution in methanol for $24 \mathrm{~h}$. The solid was then dried at $100{ }^{\circ} \mathrm{C}$ in vacuo to give PQ1 (412 mg, 93.6\%).

${ }^{1} \mathrm{H} \mathrm{NMR}\left(\mathrm{CDCl}_{3}, \delta\right): 8.25(\mathrm{~s}, 2 \mathrm{H}), 7.81-7.51(\mathrm{~m}$, $22 \mathrm{H}), 7.30-7.25(\mathrm{~m}, 6 \mathrm{H}), 7.18-7.13(\mathrm{~m}, 8 \mathrm{H})$, $6.82(\mathrm{~d}, J=6.8 \mathrm{~Hz}, 2 \mathrm{H}) .{ }^{13} \mathrm{C} \mathrm{NMR}\left(\mathrm{CDCl}_{3}, \delta\right)$ : $155.8,151.9$, 150.7, 149.5, 149.1, 149.0, 146.8, $140.7,140.3,140.1,138.7,137.9,129.6,128.9$, $128.7,128.4,128.2,127.7,127.5,127.2,126.1$, $125.9,125.1,124.6,120.9,120.1,119.0,115.7$, $65.2,65.0$. 


\section{Polyquinoline PQ2}

With the procedure described for PQ1, the polymerization of monomers 4 and 6 gave PQ2 (94.9\% yield).

${ }^{1} \mathrm{H} \mathrm{NMR}\left(\mathrm{CDCl}_{3}, \delta\right): 8.31(\mathrm{~d}, J=7.4 \mathrm{~Hz}, 2 \mathrm{H})$, $7.97(\mathrm{~d}, J=6.8 \mathrm{~Hz}, 4 \mathrm{H}), 7.87(\mathrm{~d}, J=6.7 \mathrm{~Hz}, 2 \mathrm{H})$, 7.61-7.47 (m, $10 \mathrm{H}), 7.31-7.09(\mathrm{~m}, 20 \mathrm{H}), 6.73(\mathrm{~d}$, $J=6.9 \mathrm{~Hz}, 2 \mathrm{H}) .{ }^{13} \mathrm{C} \mathrm{NMR}\left(\mathrm{CDCl}_{3}, \delta\right): 156.6$, $150.3,149.5,148.9,148.7,147.9,143.3,143.1$, $141.2,140.1,139.5,137.6,130.4,130.0,129.4$, $128.2,127.9,127.7,126.0,124.9,124.2,123.3$, $120.7,120.6,120.4,119.4,66.1,65.3$.

\section{Synthesis of Model Compound 8}

A mixture of 7 (30 mg, $81 \mu \mathrm{mol})$, 4-tert-butylacetophenone (17 mg, $98 \mu \mathrm{mol})$, DPP (146 mg, 590 $\mu \mathrm{mol})$, and freshly distilled $m$-cresol $(0.1 \mathrm{~mL})$ was flushed with nitrogen while stirring at $65{ }^{\circ} \mathrm{C}$ for about 30 min and then was heated under nitrogen at $140{ }^{\circ} \mathrm{C}$ for $12 \mathrm{~h}$. After cooling, the reaction mixture was added to water $(15 \mathrm{~mL})$ and extracted with ethyl acetate. The combined organic phases were dried $\left(\mathrm{MgSO}_{4}\right)$ and evaporated, and then the residue was purified by column chromatography (30:1 hexane/ethyl acetate) to afford compound 8 (37 mg, 89\%).

${ }^{1} \mathrm{H} \mathrm{NMR}\left(\mathrm{CDCl}_{3}, \delta\right): 8.17-8.12(\mathrm{~m}, 4 \mathrm{H}), 7.79(\mathrm{~s}$, $1 \mathrm{H})$, 7.71-7.54 (m, $8 \mathrm{H}), 7.37-7.32(\mathrm{~m}, 3 \mathrm{H})$, $2.18-2.01(\mathrm{~m}, 4 \mathrm{H}), 1.38(\mathrm{~s}, 9 \mathrm{H}), 0.80-0.67$ (m, 10 H). ${ }^{13} \mathrm{C} \mathrm{NMR}\left(\mathrm{CDCl}_{3}, \delta\right): 156.2,153.2,152.5$, $151.3,149.2,149.1,140.6,140.1,139.0,137.0$, $129.7,128.7,128.4,128.3,127.3,127.1,125.9$, 125.5, 123.5, 123.2, 120.6, 119.0, 115.0, 55.3, 43.6, 34.8, 31.4, 31.2, 17.4, 14.5. HRMS: [M $\left.{ }^{+}\right]$calcd. for $\mathrm{C}_{39} \mathrm{H}_{39} \mathrm{~N}$, 509.3082; found, 509.3097.

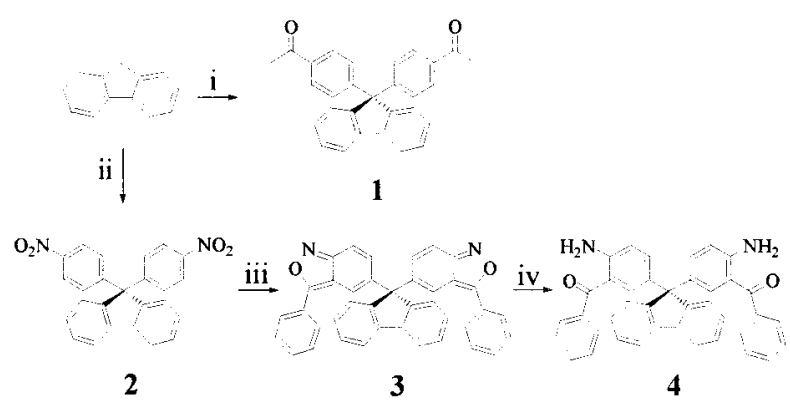

Reagents: (i) 4-fluoroacetophenone, $\mathrm{K}_{2} \mathrm{CO}_{3}$, 18-crown-6/DMF; (ii) 4-fluoronitrobenzene, $\mathrm{K}_{2} \mathrm{CO}_{3}$, 18-crown-6/DMF; (iii) benzyl cyanide, $\mathrm{NaOH} / \mathrm{CH}_{3} \mathrm{OH} / \mathrm{THF}$; (iv) $\mathrm{Fe}, \mathrm{CH}_{3} \mathrm{COOH} / \mathrm{H}_{2} \mathrm{O}$.

Scheme 1
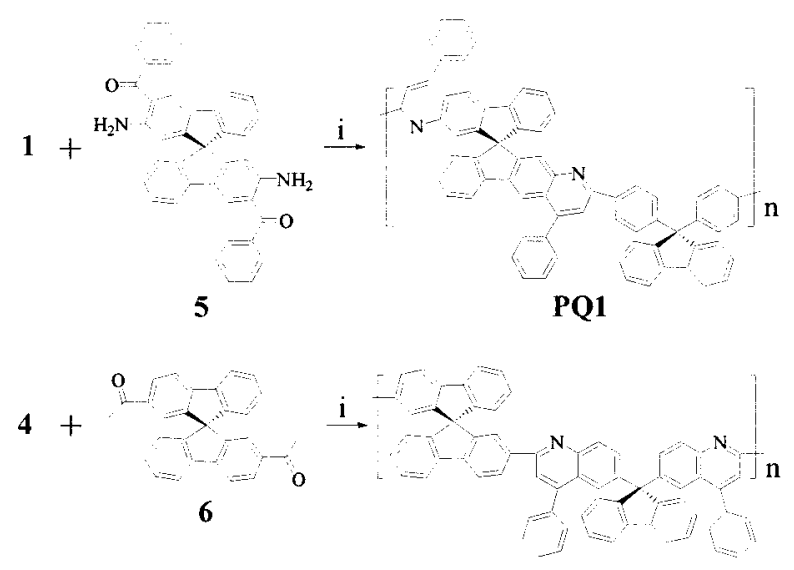

Reagents: (i) DPP/m-cresol.

PQ2

Scheme 2

\section{RESULTS AND DISCUSSION}

\section{Synthesis}

Scheme 1 illustrates the synthetic route used to prepare the fluorene-based bisacetyl (1) and bis $(o-$ aminoketone) (4) cardo monomers. Starting from fluorene, which contains an activated methylene group at the C-9 position, our synthetic strategy is based on the nucleophilic aromatic substitution of 4-fluoroarenes with the fluorenyl anion generated by $\mathrm{K}_{2} \mathrm{CO}_{3}$ in DMF. This approach is a simple and direct method for adding 4-acetylphenyl and 4-nitrophenyl functionalities to the C-9 position of fluorene for the preparation of $\mathbf{1}$ and $\mathbf{2}$, respectively; in comparison, previously reported methods for the synthesis of these compounds require

Table 1. Molecular Weights and Thermal Properties of Polyquinolines PQ1 and PQ2

\begin{tabular}{|c|c|c|c|c|c|}
\hline \multirow[b]{2}{*}{ Polymer } & \multirow[b]{2}{*}{$M_{\mathrm{n}} \times 10^{4 \mathrm{a}}$} & \multirow[b]{2}{*}{$M_{\mathrm{w}} \times 10^{4 \mathrm{a}}$} & \multirow{2}{*}{$\begin{array}{c}T_{\mathrm{g}} \\
\left({ }^{\circ} \mathrm{C}\right)^{\mathrm{b}}\end{array}$} & \multicolumn{2}{|c|}{$\begin{array}{l}\text { TGA } \\
\left({ }^{\circ} \mathrm{C}\right)^{\mathrm{c}}\end{array}$} \\
\hline & & & & $5 \%$ & $10 \%$ \\
\hline PQ1 & 1.0 & 1.4 & 440 & 619 & 689 \\
\hline $\mathrm{PQ} 2$ & 1.1 & 2.5 & $-^{\mathrm{d}}$ & 576 & 596 \\
\hline
\end{tabular}

a The molecular weights were determined by GPC in THF by comparison with polystyrene standards.

b The value of $T_{\mathrm{g}}$ was determined by DSC at heating rate of $20{ }^{\circ} \mathrm{C} \min ^{-1}$ under a nitrogen atmosphere.

c The temperatures at which 5 and $10 \%$ weight losses occurred were determined at a heating rate of $20{ }^{\circ} \mathrm{C} \mathrm{min}{ }^{-1}$ under a nitrogen atmosphere.

${ }^{\mathrm{d}}$ Phase transitions were not observed from 30 to $500{ }^{\circ} \mathrm{C}$. 


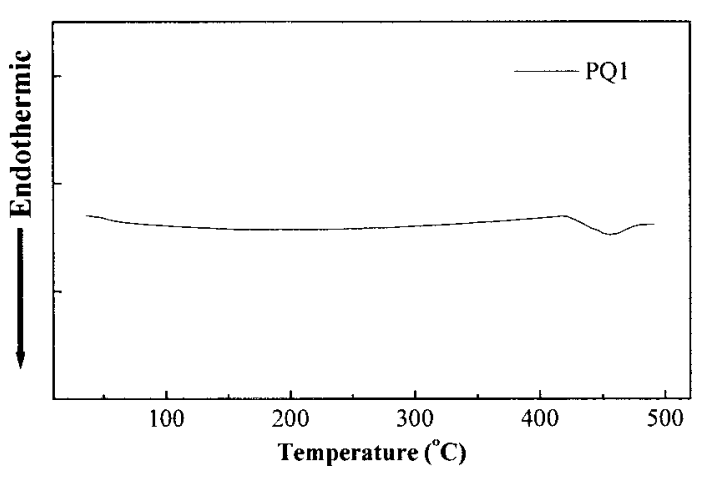

Figure 1. DSC data for PQ1 recorded under a nitrogen atmosphere.

several synthetic steps. ${ }^{30,45,46}$ The conversion of 2 into bis(o-aminoketone) monomer $\mathbf{4}$ followed a literature procedure. ${ }^{30}$ The reaction of compound 2 with benzyl cyanide in the presence of a base yielded bisbenzisoxazole $\mathbf{3}$, which was then transformed into monomer 4 by hydrogenation with iron powder in $\mathrm{AcOH}$. The structures of compounds 1-4 were verified by ${ }^{1} \mathrm{H}$ and ${ }^{13} \mathrm{C}$ NMR spectroscopy, mass spectrometry, and elemental analysis. The other two monomers, bisacetyl $\mathbf{5}$ and bis(o-aminoketone) 6, containing spirobifluorene skeletons, were prepared as reported previously. ${ }^{32}$

Polyquinolines PQ1 and PQ2 were synthesized (Scheme 2) with a condensation based on the acidcatalyzed Friedländer reaction. ${ }^{17,18}$ An equimolar mixture of the appropriate bisacetyl monomer and the bis( $o$-aminoketone) monomer was reacted in an acidic medium of DPP and $m$-cresol at 140 ${ }^{\circ} \mathrm{C}$ for $72 \mathrm{~h}$ under nitrogen. The resulting viscous polymer solution was diluted with $\mathrm{CHCl}_{3}$ and precipitated into methanol containing $10 \%$ triethylamine; this was followed by Soxhlet extraction with the same solution to afford the polyquinolines in high yields. The structures of PQ1 and PQ2 were characterized by ${ }^{1} \mathrm{H}$ and ${ }^{13} \mathrm{C}$ NMR spec- troscopy. The molecular weights of these polymers were determined by gel permeation chromatography (GPC) with THF as the eluent and with calibration against polystyrene standards; Table 1 lists the results. In the case of PQ1, the molecular weights are probably higher than the values listed because it is only partially soluble in THF; the insoluble portion corresponds to a higher molecular weight material.

\section{Properties of the Polyquinolines}

We investigated the thermal properties of the polyquinolines by DSC and TGA; the results are tabulated in Table 1. DSC was performed from 30 to $500{ }^{\circ} \mathrm{C}$. In repeated heating and cooling DSC cycles for $\mathrm{PQ} 2$, we did not detect any possible phase-transition signals. This observation probably results from the stiffness of this polymer's chains. As presented in Figure 1, we observe a distinct $T_{\mathrm{g}}$ for PQ1 at $440{ }^{\circ} \mathrm{C}$, which is higher than that of the polyquinoline, PQ3 $\left(T_{\mathrm{g}}=390{ }^{\circ} \mathrm{C}\right)$, which contains only fluorene cardo units: ${ }^{30}$

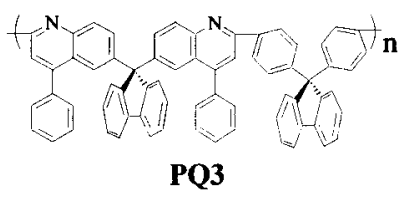

In general, the presence of bulky fluorene cardo groups, which restrict the rotation of the polymer chain, leads to polymers that have highly rigid backbones. The incorporation of rigid 9, $9^{\prime}$-spirobifluorene units into the polymer backbone further increases the chain stiffness and results in a higher $T_{\mathrm{g}}$. As evidenced from TGA, both PQ1 and PQ2 have excellent thermal stability. The 5 and $10 \%$ weight-loss temperatures in nitrogen were 576-619 and $596-689{ }^{\circ} \mathrm{C}$, respectively, and the char yields greater than $80 \%$ in nitrogen at 900 ${ }^{\circ} \mathrm{C}$. These results reflect the high thermal stabil-

Table 2. Solubility of Polyquinolines PQ1 and PQ2 ${ }^{\mathrm{a}}$

\begin{tabular}{|c|c|c|c|c|c|c|c|c|c|c|c|}
\hline \multirow[b]{2}{*}{ Polymer } & \multicolumn{11}{|c|}{ Solvent } \\
\hline & $\mathrm{CH}_{2} \mathrm{Cl}_{2}$ & $\mathrm{CHCl}_{3}$ & $\mathrm{PhCl}$ & Py & $\mathrm{THF}$ & $m$-Cresol & $\mathrm{DMF}$ & NMP & $\mathrm{HCOOH}$ & $\mathrm{AcOH}$ & $\mathrm{CF}_{3} \mathrm{COOH}$ \\
\hline PQ1 & -+ & ++ & ++ & ++ & +- & +- & -- & ++ & ++ & ++ & ++ \\
\hline PQ2 & ++ & ++ & ++ & ++ & ++ & ++ & -+ & ++ & ++ & ++ & ++ \\
\hline
\end{tabular}

${ }^{\mathrm{a}}++=$ soluble at room temperature $+-=$ soluble on heating; $-+=$ partially soluble on heating; $--=$ insoluble. 


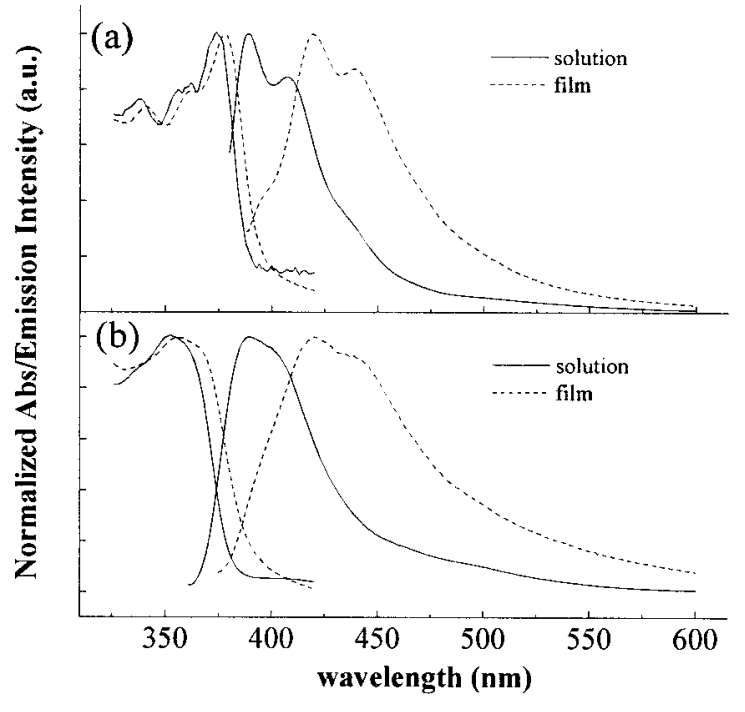

Figure 2. UV-vis absorption and PL spectra of (a) $\mathrm{PQ} 1$ and (b) $\mathrm{PQ} 2$ recorded in $\mathrm{CHCl}_{3}$ solutions and in the solid state.

ity of the cardofluorene and spirobifluorene units present in the polymer backbones.

Like most polyquinolines, $\mathrm{PQ} 1$ and $\mathrm{PQ} 2$ are soluble in protic acid solvents such as formic acid $(\mathrm{HCOOH}), \mathrm{AcOH}$, and trifluoroacetic acid $\left(\mathrm{CF}_{3} \mathrm{COOH}\right)$. The solubility of these polyquinolines was also tested in a variety of aprotic organic solvents; the results are summarized in Table 2 . The polyquinolines have improved solubility in common organic solvents such as $\mathrm{CHCl}_{3}$, pyridine (Py), and $N$-methyl-2-pyrrolidinone (NMP). PQ1 is only partially soluble in $\mathrm{CH}_{2} \mathrm{Cl}_{2}$, but PQ2 is soluble. PQ2 is soluble in THF and $m$-cresol, but PQ1 is soluble in them only at elevated temperatures. The good solubility of these aromatic polyquinolines is significant in that it does not arise from the presence of flexible ether linkages or long alkyl pendent groups; rather, their solubility appears to result from the rigid three-dimensional structures of the spirobifluorene and cardofluorene moieties in the polymer backbones. These structures hinder close packing and prevent strong interpolymer interactions, and this leads to an enhancement in solubility.

Figure 2 presents the absorption and emission spectra of the polyquinolines; these spectral properties are summarized in Table $3 . \mathrm{In} \mathrm{CHCl}_{3}$ solutions, $\mathrm{PQ} 1$ and $\mathrm{PQ} 2$ have similar lowest energy transitions, which we attribute to their $\pi-\pi^{*}$ transitions, with maximum wavelengths $\left(\lambda_{\max }\right)$ of 374 and $352 \mathrm{~nm}$, respectively. The emission maxima are $389 \mathrm{~nm}$ (408 nm, shoulder) for the former and $391 \mathrm{~nm}$ for the latter. The shoulder at $408 \mathrm{~nm}$ is associated with a vibronic fine structure, which indicates that the polymer has a rigid and welldefined backbone. ${ }^{42}$ The PL quantum yields of $\mathrm{PQ} 1$ and $\mathrm{PQ} 2$ in $\mathrm{CHCl}_{3}$ solutions were estimated to be 0.27 and 0.24 , respectively, with respect to the standard 9,10-diphenylanthracene (ca. 5 $\times 10^{-6} \mathrm{M}$ solution in cyclohexane, with a fluorescence quantum yield of 0.90). ${ }^{47}$ The absorption spectra of the solutions and their corresponding films are nearly identical, whereas the emission from films is redshifted with respect to that obtained from dilute solutions. This most likely results from either intermolecularly interacting species, namely aggregates and excimers, or a change in the polymer conformation in the solid state. ${ }^{48,49}$ The redshift of the emission spectrum in the thin film has also been seen for other rigidrod polyquinolines. ${ }^{27,32}$

To demonstrate that the $\mathrm{sp}^{3}$-hybridized carbon atoms at the centers of both the spiro and cardo moieties could serve as conjugation interrupts controlling the conjugation length of the polymers, we synthesized model compound 8 (Scheme 3 ) to act as the repetitive conjugated unit of polymer PQ1. As shown in Figure 3, the UV-vis ab-

Table 3. Optical Properties of Polyquinolines PQ1 and PQ2

\begin{tabular}{|c|c|c|c|c|}
\hline \multirow[b]{2}{*}{ Polymer } & \multicolumn{2}{|c|}{$\begin{array}{c}\text { Absorption } \\
\lambda_{\max }(\mathrm{nm})\end{array}$} & \multicolumn{2}{|c|}{$\begin{array}{c}\text { Photoluminescence } \\
\lambda_{\max }(\mathrm{nm}) \\
\end{array}$} \\
\hline & Solution $^{a}$ & Film $^{\mathrm{b}}$ & Solution $^{\mathrm{a}}$ & Film $^{\mathrm{b}}$ \\
\hline PQ1 & 374 & 377 & $389,408(\mathrm{sh})$ & 419,439 (sh) \\
\hline $\mathrm{PQ} 2$ & 352 & 359 & 391 & $420,442(\mathrm{sh})$ \\
\hline
\end{tabular}




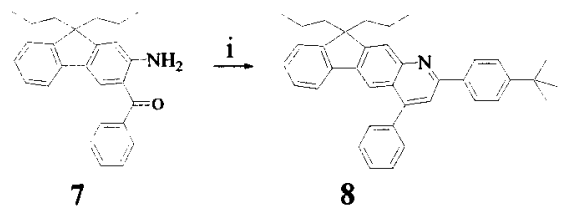

Reagents: (i) 4'-tert-butylacetophenone, DPP/m-cresol.

Scheme 3

sorption and $\mathrm{PL}$ spectra of $\mathrm{PQ} 1$ in $\mathrm{CHCl}_{3}$ closely resemble those obtained from compound $\mathbf{8}$, and this indicates that the effective conjugation length of PQ1 is controlled well by the $\mathrm{sp}^{3}$-hybridized carbon atoms and is nearly identical to that of compound $\mathbf{8}$.

The electrochemical behavior of the polyquinolines was investigated with cyclic voltammetry, with ferrocene as the internal standard. The cyclic voltammograms of $\mathrm{PQ} 1$ and $\mathrm{PQ} 2$ are displayed in Figure 4, and the data are tabulated in Table 4. Upon cathodic sweeps, PQ1 and PQ2 exhibit quasireversible reductions with onsets at about -2.10 and $-2.13 \mathrm{~V}$, respectively; the oxidation processes of these polymers are irreversible, with onsets at about 1.10 and $1.13 \mathrm{~V}$, respectively. On the basis of the onset potentials of the oxidation and reduction processes, we estimated the highest orbital molecular orbital (HOMO) and lowest unoccupied molecular orbital (LUMO) energy levels of the polyquinolines with respect to the energy level of the ferrocene (FOC) reference $\left(4.8 \mathrm{eV}\right.$ below the vacuum level) ${ }^{50}$ Table 4 summarizes these values. The HOMO-LUMO energy gaps estimated from the oxidation and reduction potentials are in close agreement with those de-

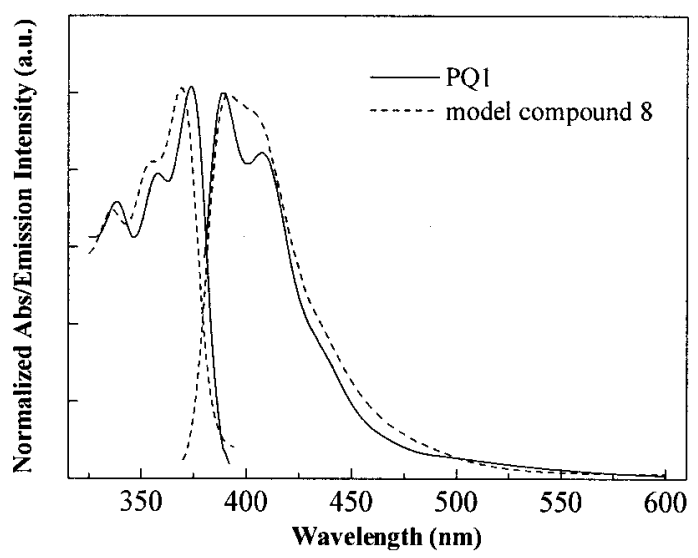

Figure 3. UV-vis absorption and PL spectra of model compound 8 and $\mathrm{PQ1}$ recorded in $\mathrm{CHCl}_{3}$.

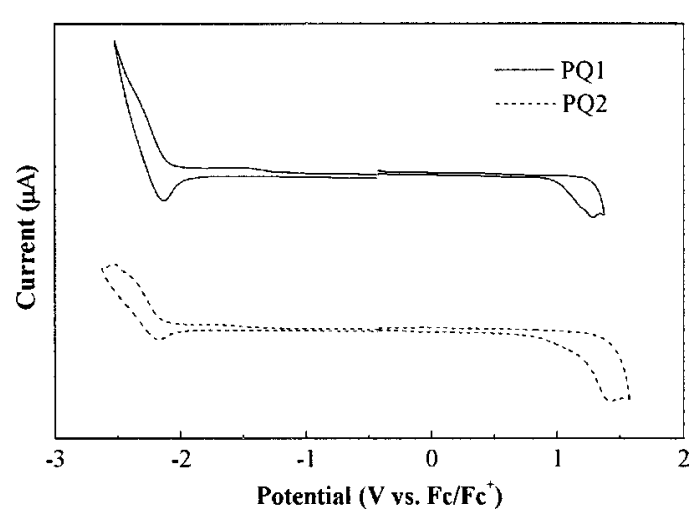

Figure 4. Cyclic voltammograms recorded in $\mathrm{CH}_{3} \mathrm{CN}$ for PQ1 and PQ2 films coated on a glassy carbon electrode.

termined from the edges of the electronic absorption bands. The low-lying LUMO energy levels, which originate from the electron-deficient nature of the quinoline ring, are similar to those of typical quinoline-containing polymers. ${ }^{2,5}$ From the quasireversible reduction and high electron affinity, we believe that $\mathrm{PQ} 1$ and $\mathrm{PQ} 2$ have potential for use as electron-injecting/transporting materials in polymer light-emitting diodes.

\section{CONCLUSIONS}

We have reported a direct and simple method for the synthesis of bis(o-aminoketone) and bisacetyl monomers containing cardo fluorenyl groups. The cardo-type bis(o-aminoketone) monomer, $\mathrm{A}-\mathrm{A}$ (or bisacetyl, B-B), is in turn subjected to polycondensation with a bisacetyl monomer, B-B [or bis(o-aminoketone), A-A], possessing a spirobifluorene linkage to furnish polyquinolines with both spirobifluorene and cardofluorene moieties in their main chains. As a result of the incorporation of these rigid, nonplanar structures into the polymer backbone, the polyquinolines possess enhanced thermal stability and improved solubility with respect to regular polyquinolines. These new polymers have similar lowest energy transitions, which we attribute to their $\pi-\pi^{*}$ transitions, with values of $\lambda_{\max }$ in the range $352-374 \mathrm{~nm}$; their polymer films exhibit blue emissions. We have also synthesized a model compound to demonstrate that the $\mathrm{sp}^{3}$-hybridized carbon atoms at the centers of the spiro and cardo moieties serve as a 
Table 4. Electrochemical Properties of Polyquinolines PQ1 and PQ2

\begin{tabular}{ccccccc}
\hline Polymer & $E_{\text {onset }^{\text {ox }}(\mathrm{V})^{\mathrm{a}}}$ & $E_{\text {onset }}^{\text {red }}(\mathrm{V})^{\mathrm{a}}$ & HOMO $(\mathrm{eV})^{\mathrm{b}}$ & $\mathrm{LUMO}_{(\mathrm{eV})^{\mathrm{c}}}$ & $E_{\mathrm{g}}{ }^{\mathrm{el}}(\mathrm{eV})^{\mathrm{d}}$ & $E_{\mathrm{g}}{ }^{\mathrm{opt}}(\mathrm{eV})^{\mathrm{e}}$ \\
\hline PQ1 & 1.00 & -2.10 & -5.80 & -2.70 & 3.10 & 3.11 \\
PQ2 & 1.13 & -2.13 & -5.93 & -2.67 & 3.26 & 3.24 \\
\hline
\end{tabular}

a Potential values determined versus $\mathrm{Fc} / \mathrm{Fc}^{+}$.

b Determined from the onset oxidation potential.

${ }^{\mathrm{c}}$ Determined from the onset reduction potential.

d Electrochemical band gap, estimated with the equation $E_{\mathrm{g}}{ }^{\text {el }}=E_{\text {onset }}{ }^{\text {ox }}-E_{\text {onset }}^{\text {red }}$.

e Optical band gap, calculated from the absorption edge of the UV-vis spectrum.

conjugation interrupts that effectively control the conjugation length of the polymers. The electrochemical behavior of these polymers has been investigated with cyclic voltammetry, which indicates that the polyquinolines have potential to be used as electron-injecting/transporting materials in polymer light-emitting diodes.

The authors thank the National Science Council of the Republic of China for its financial support.

\section{REFERENCES AND NOTES}

1. Stille, J. K. Macromolecules 1981, 14, 870.

2. Agrawal, A. K.; Jenekhe, S. A. Chem Mater 1996, 8, 579.

3. Zhang, X.; Shetty, A. S.; Jenekhe, S. A. Macromolecules 1999, 32, 7422 .

4. Parker, I. D.; Pei, Q.; Marrocco, M. Appl Phys Lett 1994, 65, 1272.

5. Jenekhe, S. A.; Zhang, X.; Chen, X. L. Chem Mater 1997, 9, 409.

6. Kim, J. L.; Kim, J. K.; Cho, H. N.; Kim, D. Y.; Kim, C. Y.; Hong, S. I. Macromolecules 2000, 33, 5880.

7. Liu, Y. Q.; Ma, H.; Jen, A. K. Y. J Mater Chem 2001, 11, 1800 .

8. Zhan, X. W.; Liu, Y. Q.; Wu, X.; Wang, S. A.; Zhu, D. B. Macromolecules 2002, 35, 2529.

9. Akcelrud, L. Prog Polym Sci 2003, 28, 875.

10. Kulkarni, A. P.; Jenekhe, S. A. Macromolecules 2003, 36, 5285.

11. Alam, M. M.; Tonzola, C. J.; Jenekhe, S. A. Macromolecules 2003, 36, 6577.

12. Zhu, Y.; Alam, M. M.; Jenekhe, S. A. Macromolecules 2003, 36, 8958.

13. Babel, A.; Jenekhe, S. A. J Am Chem Soc 2003, 125, 13656.

14. Alam, M. M.; Jenekh, S. A. J Phys Chem B 2001, 105, 2479.

15. Agrawal, A. K.; Jenekhe, S. A.; Vanherzeele, H.; Meth, J. S. Chem Mater 1991, 3, 765.
16. Agrawal, A. K.; Jenekhe, S. A. Macromolecules 1993, 26, 895.

17. Jen, A. K.-Y.; Wu, X.-M.; Ma, H. Chem Mater 1998, $10,471$.

18. Ma, H.; Jen, A. K.-Y.; Wu, J.; Wu, X.; Liu, S.; Shu, C.-F.; Dalton, L. R.; Marder, S. R.; Thayumanavan, S. Chem Mater 1999, 11, 2218.

19. Stenger-Smith, J. D.; Zarras, P.; Hollins, R. A.; Chafin, A. P.; Merwin, L. H.; Yee, R.; Lindsay, G. A.; Herman, W. N.; Gratz, R. F.; Nickel, E. G. J Polym Sci Part A: Polym Chem 2000, 38, 2824.

20. Gubbelmans, E.; Van den Broeck, K.; Verbiest, T.; Van Beylen, M.; Persoons, A.; Samyn, C. Eur Polym J 2003, 39, 969.

21. Zhan, X. W.; Liu, Y. Q.; Zhu, D. B.; Xu, G.; Liu, X. C.; Ye, P. X. Appl Phys A 2003, 77, 375.

22. Lee, T. S.; Yang, C.; Kim, J. L.; Lee, J. K.; Park, W. H.; Won, Y. J Polym Sci Part A: Polym Chem 2002, 40, 1831.

23. Tong, H.; Wang, L. X.; Jing, X. B.; Wang, F. Macromolecules 2002, 35, 7169.

24. Tong, H.; Wang, L. X.; Jing, X. B.; Wang, F. Macromol Rapid Commun 2002, 23877.

25. Sutherlin, D. M.; Stille, J. K. Macromolecules 1985, 18, 2669.

26. Agrawal, A. K.; Jenekhe, S. A. Chem Mater 1992, 4, 95.

27. Tonzola, C. J.; Alam, M. M.; Jenekhe, S. A. Adv Mater 2002, 14, 1086.

28. Krüger, H.; Janietz, S.; Sainova, D.; Wedel, A. Macromol Chem Phys 2003, 2041607.

29. Sutherlin, D. M.; Stille, J. K. Macromolecules 1985, $18,2669$.

30. Stille, J. K.; Harris, R. M.; Padaki, S. M. Macromolecules 1981, 14, 486.

31. Concilio, S.; Pfister, P. M.; Tirelli, N.; Kocher, C.; Suter, U. W. Macromolecules 2001, 34, 3607.

32. Chiang, C.-L.; Shu, C.-F. Chem Mater 2002, 14, 682.

33. Imai, Y.; Johnson, E. P.; Katto, T.; Kurihara, M.; Stille, J. K. J Polym Sci Polym Chem Ed 1975, 13, 2233. 
34. Wolfe, J. F.; Stille, J. K. Macromolecules 1976, 9, 489.

35. Norris, S. O.; Stille, J. K. Macromolecules 1976, 9, 496.

36. Wu, R.; Schumm, J. S.; Pearson, D. L.; Tour, J. M. J Org Chem 1996, 61, 6906.

37. Salbeck, J.; Bauer, J.; Weissörtel, F. Macromol Symp 1997, 125, 121.

38. Chou, C.-H.; Reddy, D. S.; Shu, C.-F. J Polym Sci Part A: Polym Chem 2002, 40, 3615.

39. Wu, S.-C.; Shu, C.-F. J Polym Sci Part A: Polym Chem 2003, 41, 1160.

40. Korshak, V. V.; Vinogradova, S. V.; Vygodskii, Y. S. J Macromol Sci Rev Macromol Chem 1974, 11,45 .

41. Stevens, M. P. Polymer Chemistry: An Introduction, 2nd ed.; Oxford University Press: New York, 1990; p 124.
42. Wu, F.-I.; Dodda, R.; Reddy, D. S.; Shu, C.-F. J Mater Chem 2002, 12, 2893.

43. Gilchrist, T. L. Heterocyclic Chemistry; Wiley: New York, 1985.

44. Haas, G.; Prolog, V. Helv Chim Acta 1969, 52, 1202.

45. Harris, R. M.; Padaki, S.; Sybert, P.; Stille, J. K. Polym Prepr 1978, 19, 7.

46. Milstein, D.; Stille, J. K. J Org Chem 1979, 44, 1613.

47. Eaton, D. Pure Appl Chem 1998, 60, 1107.

48. Jenekhe, S. A.; Osaheni, J. A. Science 1994, 265, 765 .

49. Osaheni, J. A.; Jenekhe, S. A. Macromolecules 1994, 27, 739 .

50. Pommerehne, J.; Vestweber, H.; Guss, W.; Mahrt, R. F.; Bässler, H.; Porsch, M.; Daub, J. Adv Mater 1995, 7, 551 . 